\title{
Hybrid Algorithm for Common Fixed Points of Uniformly Closed Countable Families of Hemirelatively Nonexpansive Mappings and Applications
}

\author{
Sumei $\mathrm{Ai}^{1}$ and Yongfu $\mathrm{Su}^{2}$ \\ ${ }^{1}$ Department of Mathematics, Cangzhou Normal University, Cangzhou 061001, China \\ ${ }^{2}$ Department of Mathematics, Tianjin Polytechnic University, Tianjin 300387, China
}

Correspondence should be addressed to Yongfu Su, suyongfu@tjpu.edu.cn

Received 27 November 2011; Accepted 15 December 2011

Academic Editor: Yonghong Yao

Copyright (C) 2012 S. Ai and Y. Su. This is an open access article distributed under the Creative Commons Attribution License, which permits unrestricted use, distribution, and reproduction in any medium, provided the original work is properly cited.

The authors have obtained the following results: (1) the definition of uniformly closed countable family of nonlinear mappings, (2) strong convergence theorem by the monotone hybrid algorithm for two countable families of hemirelatively nonexpansive mappings in a Banach space with new method of proof, (3) two examples of uniformly closed countable families of nonlinear mappings and applications, (4) an example which is hemirelatively nonexpansive mapping but not weak relatively nonexpansive mapping, and (5) an example which is weak relatively nonexpansive mapping but not relatively nonexpansive mapping. Therefore, the results of this paper improve and extend the results of Plubtieng and Ungchittrakool (2010) and many others.

\section{Introduction and Preliminaries}

Let $E$ be a Banach space with the dual $E^{*}$. We denote by $J$ the normalized duality mapping from $E$ to $2^{E^{*}}$ defined by

$$
J x=\left\{f \in E^{*}:\langle x, f\rangle=\|x\|^{2}=\|f\|^{2}\right\},
$$

where $\langle\cdot, \cdot\rangle$ denotes the generalized duality pairing. It is well known that the normalized duality $J$ has the following properties: (1) if $E$ is smooth, then $J$ is single valued; (2) if $E$ is strictly convex, then $J$ is one-to-one (i.e., $J x \cap J y=\emptyset$ for all $x \neq y$ ); (3) if $E$ is reflexive, then $J$ is surjective; (4) if $E$ has Frchet differentiable norm, then $J$ is uniformly norm-to-norm 
continuous; (5) if $E$ is uniformly smooth, then $J$ is uniformly norm-to-norm continuous on each bounded subset of $E$; (7) if $E$ is a Hilbert space, then $J$ is the identity operator.

As we all know that if $C$ is a nonempty closed convex subset of a Hilbert space $H$ and $P_{C}: H \rightarrow C$ is the metric projection of $H$ onto $C$, then $P_{C}$ is nonexpansive. This fact actually characterizes Hilbert spaces, and, consequently, it is not available in more general Banach spaces. In this connection, Alber [1] has recently introduced a generalized projection operator $\Pi_{C}$ in a Banach space $E$ which is an analogue of the metric projection in Hilbert spaces.

Let $E$ be a smooth Banach space. Consider the function defined by

$$
\phi(x, y)=\|x\|^{2}-2\langle x, J y\rangle+\|y\|^{2} \text { for } x, y \in E .
$$

Observe that, in a Hilbert space $H,(1.2)$ reduces to $\phi(x, y)=\|x-y\|^{2}, x, y \in H$.

The generalized projection $\Pi_{C}: E \rightarrow C$ is a map that assigns to an arbitrary point $x \in E$ the minimum point of the functional $\phi(x, y)$, that is, $\Pi_{C} x=\bar{x}$, where $\bar{x}$ is the solution to the minimization problem

$$
\phi(\bar{x}, x)=\min _{y \in C} \phi(y, x)
$$

existence and uniqueness of the operator $\Pi_{C}$ follow from the properties of the functional $\phi(x, y)$ and strict monotonicity of the mapping $J$ (see, e.g., $[1,2]$ ). In Hilbert space, $\Pi_{C}=P_{C}$. It is obvious from the definition of function $\phi$ that

$$
(\|y\|-\|x\|)^{2} \leq \phi(y, x) \leq(\|y\|+\|x\|)^{2} \quad \forall x, y \in E
$$

If $E$ is a reflexive strictly convex and smooth Banach space, then for $x, y \in E, \phi(x, y)=0$ if and only if $x=y$. It is sufficient to show that if $\phi(x, y)=0$, then $x=y$. From (1.4), we have $\|x\|=\|y\|$. This implies that $\langle x, J y\rangle=\|x\|^{2}=\|J y\|^{2}$. From the definitions of $j$, we have $J x=J y$. That is, $x=y$; see $[3,4]$ for more details.

Let $C$ be a closed convex subset of $E$, and let $T$ be a mapping from $C$ into itself with nonempty set of fixed points. We denote by $F(T)$ the set of fixed points of $T$. $T$ is called hemirelatively nonexpansive if $\phi(p, T x) \leq \phi(p, x)$ for all $x \in C$ and $p \in F(T)$.

A point $p$ in $C$ is said to be an asymptotic fixed point of $T$ if $C$ contains a sequence $\left\{x_{n}\right\}$ which converges weakly to $p$ such that the strong $\lim _{n \rightarrow \infty}\left(T x_{n}-x_{n}\right)=0$. The set of asymptotic fixed points of $T$ will be denoted by $\widehat{F}(T)$. A hemi-relatively nonexpansive mapping $T$ from $C$ into itself is called relatively nonexpansive if $\widehat{F}(T)=F(T)$ (see, [5]).

A point $p$ in $C$ is said to be a strong asymptotic fixed point of $T$ if $C$ contains a sequence $\left\{x_{n}\right\}$ which converges strongly to $p$ such that the strong $\lim _{n \rightarrow \infty}\left(T x_{n}-x_{n}\right)=0$. The set of strong asymptotic fixed points of $T$ will be denoted by $\widetilde{F}(T)$. A hemi-relatively nonexpansive mapping $T$ from $C$ into itself is called weak relatively nonexpansive if $\widetilde{F}(T)=F(T)$ (see, [6]).

The following conclusions are obvious: (1) relatively nonexpansive mapping must be weak relatively nonexpansive mapping; (2) weak relatively nonexpansive mapping must be hemi-relatively nonexpansive mapping.

In this paper, we will give two examples to show that the inverses of above two conclusions are not hold. 
In an infinite-dimensional Hilbert space, Mann's iterative algorithm has only weak convergence, in general, even for nonexpansive mappings. Hence in order to have strong convergence, in recent years, the hybrid iteration methods for approximating fixed points of nonlinear mappings has been introduced and studied by various authors.

In 2003, Nakajo and Takahashi [7] proposed the following modification of Mann iteration method for a single nonexpansive mapping $T$ in a Hilbert space $H$ :

$$
\begin{aligned}
x_{0} & \in C \text { chosen only arbitrarily, } \\
y_{n} & =\alpha_{n} x_{n}+\left(1-\alpha_{n}\right) T x_{n}, \\
C_{n} & =\left\{z \in C:\left\|y_{n}-z\right\| \leq\left\|x_{n}-z\right\|\right\}, \\
Q_{n} & =\left\{z \in C:\left\langle x_{n}-z, x_{0}-x_{n}\right\rangle \geq 0\right\}, \\
x_{n+1} & =P_{C_{n} \cap Q_{n}}\left(x_{0}\right),
\end{aligned}
$$

where $C$ is a closed convex subset of $H$, and $P_{K}$ denotes the metric projection from $H$ onto a closed convex subset $K$ of $H$. They proved that if the sequence $\left\{\alpha_{n}\right\}$ is bounded above from one, then the sequence $\left\{x_{n}\right\}$ generated by (1.5) converges strongly to $P_{F(T)}\left(x_{0}\right)$, where $F(T)$ denote the fixed points set of $T$.

The ideas to generalize the process (1.5) from Hilbert space to Banach space have recently been made. By using available properties on uniformly convex and uniformly smooth Banach space, Matsushita and Takahashi [8] presented their ideas as the following method for a single relatively nonexpansive mapping $T$ in a Banach space $E$ :

$$
\begin{aligned}
x_{0} & \in C \text { chosen only arbitrarily, } \\
y_{n} & =J^{-1}\left(\alpha_{n} J x_{0}+\left(1-\alpha_{n}\right) J T x_{n}\right), \\
C_{n} & =\left\{z \in C: \phi\left(z, y_{n}\right) \leq \phi\left(z, x_{n}\right)\right\}, \\
Q_{n} & =\left\{z \in C:\left\langle x_{n}-z, J x_{0}-J x_{n}\right\rangle \geq 0\right\}, \\
x_{n+1} & =\prod_{C_{n} \cap Q_{n}}\left(x_{0}\right),
\end{aligned}
$$

where $J$ is the duality mapping on $E$, and $\Pi_{K}(\cdot)$ is the generalized projection from $E$ onto a nonempty closed convex subset $K$. They proved the following convergence theorem.

Theorem MT. Let E be a uniformly convex and uniformly smooth Banach space, let $C$ be a nonempty closed convex subset of $E$, let $T$ be a relatively nonexpansive mapping from $C$ into itself, and let $\left\{\alpha_{n}\right\}$ be a sequence of real numbers such that $0 \leq \alpha_{n}<1$ and $\limsup _{n \rightarrow \infty} \alpha_{n}<1$. Suppose that $\left\{x_{n}\right\}$ is given by (1.6), where $J$ is the duality mapping on $E$. If $F(T)$ is nonempty, then $\left\{x_{n}\right\}$ converges strongly to $\Pi_{F(T)} x_{0}$, where $\Pi_{F(T)}(\cdot)$ is the generalized projection from $C$ onto $F(T)$.

Recently, Plubtieng and Ungchittrakool [9] here proposed the following hybrid iteration method for a countable family of relatively nonexpansive mappings in a Banach space and proved the convergence theorem. 
Theorem PU. Let E be a uniformly smooth and uniformly convex Banach space and let $\widehat{C}$ and $C$ be two nonempty closed convex subsets of $E$ such that $\widehat{C} \subset C$. Let $\left\{T_{n}\right\}$ be a sequence of relatively nonexpansive mappings from $C$ into $E$ such that $\bigcap_{n=1}^{\infty} F\left(T_{n}\right)$ is nonempty, and let $\left\{x_{n}\right\}$ be a sequence defined as follows:

$$
\begin{aligned}
x_{0} & \in \widehat{C}, \\
C_{1} & =C \\
x_{1} & =\Pi_{C_{1}} x_{0} \\
y_{n} & =J^{-1}\left(\alpha_{n} J x_{n}+\left(1-\alpha_{n}\right) J T_{n} x_{n}\right), \\
C_{n+1} & =\left\{z \in C_{n}: \phi\left(z, y_{n}\right) \leq \phi\left(z, x_{n}\right)\right\}, \quad n \geq 1, \\
x_{n+1} & =\Pi_{C_{n+1}} x_{0},
\end{aligned}
$$

where $\alpha_{n} \in[0,1]$ satisfies either

(a) $0 \leq \alpha_{n}<1$ for all $n \geq 1$ and $\lim \sup _{n \rightarrow \infty} \alpha_{n}<1$ or

(b) $\liminf _{n \rightarrow \infty} \alpha_{n}\left(1-\alpha_{n}\right)>0$.

Suppose that for any bounded subset $B$ of $C$ there exists an increasing, continuous and convex function $h_{B}$ from $R^{+}$into $R^{+}$such that $h_{B}(0)=0$, and

$$
\lim _{l, k \rightarrow \infty} \sup \left\{h_{B}\left(\left\|T_{l} z-T_{k} z\right\|\right): z \in B\right\}=0 .
$$

Let $T$ be a mapping from $C$ into $E$ defined by $T x=\lim _{n \rightarrow \infty} T_{n} x$ for all $x \in C$ and suppose that

$$
F(T)=\bigcap_{n=1}^{\infty} F\left(T_{n}\right)=\bigcap_{n=1}^{\infty} \widehat{F}\left(T_{n}\right)=\widehat{F}(T) .
$$

Then $\left\{x_{n}\right\},\left\{T_{n} x_{n}\right\}$, and $\left\{y_{n}\right\}$ converge strongly to $\Pi_{F(T)} x_{0}$.

In this paper, the authors have obtained the following results: (1) the definition of uniformly closed countable family of nonlinear mappings, (2) strong convergence theorem by the monotone hybrid algorithm for a countable family of hemi-relatively nonexpansive mappings in a Banach space with new method of proof, (3) two examples of uniformly closed countable families of nonlinear mappings and applications, (4) an example which is hemirelatively nonexpansive mapping but not weak relatively nonexpansive mapping, and (5) an example which is weak relatively nonexpansive mapping but not relatively nonexpansive mapping. Therefore, the results of this paper improve and extend the results of Plubtieng and Ungchittrakool [9] and many others.

We need the following definitions and lemmas.

Lemma 1.1 (Kamimura and Takahashi [10]). Let E be a uniformly convex and smooth Banach space, and let $\left\{x_{n}\right\}$ and $\left\{y_{n}\right\}$ be two sequences of $E$. If $\phi\left(x_{n}, y_{n}\right) \rightarrow 0$ and either $\left\{x_{n}\right\}$ or $\left\{y_{n}\right\}$ is bounded, then $x_{n}-y_{n} \rightarrow 0$. 
Lemma 1.2 (Alber [1]). Let $C$ be a nonempty closed convex subset of a smooth Banach space E and $x \in E$. Then, $x_{0}=\Pi_{C} x$ if and only if

$$
\left\langle x_{0}-y_{1} J x-J x_{0}\right\rangle \geq 0 \quad \text { for } y \in C
$$

Lemma 1.3 (Alber [1]). Let $E$ be a reflexive, strictly convex, and smooth Banach space, let $C$ be a nonempty closed convex subset of $E$, and let $x \in E$. Then

$$
\phi\left(y, \Pi_{C} x\right)+\phi\left(\Pi_{C} x, x\right) \leq \phi(y, x) \quad \forall y \in C .
$$

The following lemma is not hard to prove.

Lemma 1.4. Let $E$ be a strictly convex and smooth Banach space, let $C$ be a closed convex subset of $E$, and let $T$ be a hemi-relatively nonexpansive mapping from $C$ into itself. Then $F(T)$ is closed and convex. as follows.

In this paper, we present the definition of uniformly closed for a sequence of mappings

Definition 1.5. Let $E$ be a Banach space, $C$ be a closed convex subset of $E$, let $\left\{T_{n}\right\}_{n=1}^{\infty}$ be a sequence of mappings of $C$ into $E$ such that $\bigcap_{n=1}^{\infty} F\left(T_{n}\right)$ is nonempty. We say that $\left\{T_{n}\right\}_{n=1}^{\infty}$ is uniformly closed if $p \in \bigcap_{n=1}^{\infty} F\left(T_{n}\right)$ whenever $\left\{x_{n}\right\} \subset C$ converges strongly to $p$ and $\| x_{n}-$ $T_{n} x_{n} \| \rightarrow 0$ as $n \rightarrow \infty$.

Lemma 1.6 (see $[11,12])$. Let E be a p-uniformly convex Banach space with $p \geq 2$. Then, for all $x, y \in E, j(x) \in J_{p}(x)$, and $j(y) \in J_{p}(y)$,

$$
\langle x-y, j(x)-j(y)\rangle \geq \frac{c^{p}}{c^{p-2} p}\|x-y\|^{p}
$$

where $J_{p}$ is the generalized duality mapping from $E$ into $E^{*}$, and $1 / c$ is the $p$-uniformly convexity constant of $E$.

\section{Main Results}

Definition 2.1. Let $E$ be a Banach space, let $C$ be a nonempty closed convex subset of $E$, and let $\left\{T_{n}\right\}_{n=1}^{\infty}: C \rightarrow E,\left\{S_{n}\right\}_{n=1}^{\infty}: C \rightarrow E$ be two sequences of mappings. If for any convergence sequence $\left\{x_{n}\right\} \subset C$, the following holds:

$$
\lim _{n \rightarrow+\infty}\left\|T_{n} x_{n}-S_{n} x_{n}\right\|=0 .
$$

Then $\left\{T_{n}\right\}$ and $\left\{S_{n}\right\}$ are said to satisfy the only asymptotically condition.

Theorem 2.2. Let $E$ be a uniformly convex and uniformly smooth Banach space, let $C$ be a nonempty closed convex subset of $E$, let $\left\{T_{n}\right\}_{n=1}^{\infty}: C \rightarrow E,\left\{S_{n}\right\}_{n=1}^{\infty}: C \rightarrow E$ be two uniformly closed sequences of hemi-relatively nonexpansive mappings satisfying the asymptotically condition such that 
$F_{1}=\bigcap_{n=1}^{\infty} F\left(T_{n}\right) \neq \emptyset, F_{2}=\bigcap_{n=1}^{\infty} F\left(S_{n}\right) \neq \emptyset$, and $F=F_{1} \cap F_{2} \neq \emptyset$. Assume that $\left\{\alpha_{n}\right\}_{n=0}^{\infty},\left\{\beta_{n}\right\}_{n=0}^{\infty}$, $\left\{\gamma_{n}\right\}_{n=0}^{\infty}$ and $\left\{\delta_{n}\right\}_{n=0}^{\infty}$ are four sequences in $[0,1]$ such that $\alpha_{n}+\beta_{n}+\gamma_{n}+\delta_{n}=1, \lim _{n \rightarrow \infty} \alpha_{n}=0$ and $0<\gamma \leq \gamma_{n} \leq 1, \delta_{n} \rightarrow 0$ for some constant $\gamma \in(0,1)$. Define a sequence $\left\{x_{n}\right\}$ in $C$ by the following algorithm:

$$
\begin{aligned}
x_{0} & \in C \text { arbitrarily, } \\
y_{n} & =J^{-1}\left(\alpha_{n} J x_{0}+\beta_{n} J x_{n}+\gamma_{n} J T_{n} x_{n}+\delta_{n} J S_{n} x_{n}\right), \quad n \geq 1, \\
C_{n} & =\left\{z \in C_{n-1}: \phi\left(z, y_{n}\right) \leq\left(1-\alpha_{n}\right) \phi\left(z, x_{n}\right)+\alpha_{n} \phi\left(z, x_{0}\right)\right\}, \quad n \geq 1, \\
C_{0} & =C, \\
x_{n+1} & =\Pi_{C_{n}} x_{0}, \quad n \geq 0 .
\end{aligned}
$$

Then $\left\{x_{n}\right\}$ converges strongly to $q=\Pi_{F} x_{0}$.

Proof. We first show that $C_{n}$ is closed and convex for all $n \geq 0$. From the definitions of $C_{n}$, it is obvious that $C_{n}$ is closed for all $n \geq 0$. Next, we prove that $C_{n}$ is convex for all $n \geq 0$. Since

$$
\phi\left(z, y_{n}\right) \leq\left(1-\alpha_{n}\right) \phi\left(z, x_{n}\right)+\alpha_{n} \phi\left(z, x_{0}\right)
$$

is equivalent to

$$
2\left\langle z,\left(1-\alpha_{n}\right) J x_{n}+\alpha_{n} J x_{0}-J y_{n}\right\rangle \leq\left(1-\alpha_{n}\right)\left\|x_{n}\right\|^{2}+\alpha_{n}\left\|x_{0}\right\|^{2}-\left\|y_{n}\right\|^{2},
$$

it is easy to get that $C_{n}$ is convex for all $n \geq 0$.

Next, we show that $F \subset C_{n}$ for all $n \geq 1$. Indeed, for each $p \in F$, we have

$$
\begin{aligned}
\phi\left(p, y_{n}\right)= & \phi\left(p, J^{-1}\left(\alpha_{n} J x_{0}+\beta_{n} J x_{n}+\gamma_{n} J T_{n} x_{n}+\delta_{n} J S_{n} x_{n}\right)\right) \\
= & \|p\|^{2}-2\left\langle p,\left(\alpha_{n} J x_{0}+\beta_{n} J x_{n}+\gamma_{n} J T_{n} x_{n}+\delta_{n} J S_{n} x_{n}\right)\right\rangle \\
& +\left\|\alpha_{n} J x_{0}+\beta_{n} J x_{n}+\gamma_{n} J T_{n} x_{n}+\delta_{n} J S_{n} x_{n}\right\|^{2} \\
\leq & \|p\|^{2}-2 \alpha_{n}\left\langle p, J x_{0}\right\rangle-2 \beta_{n}\left\langle p, J x_{n}\right\rangle-2 \gamma_{n}\left\langle p, J T_{n} x_{n}\right\rangle-2 \delta_{n}\left\langle p, J S_{n} x_{n}\right\rangle \\
& +\alpha_{n}\left\|x_{0}\right\|^{2}+\beta_{n}\left\|x_{n}\right\|+\gamma_{n}\left\|T_{n} x_{n}\right\|^{2}+\delta_{n}\left\|S_{n} x_{n}\right\|^{2} \\
\leq & \alpha_{n} \phi\left(p, x_{0}\right)+\beta_{n} \phi\left(p, x_{n}\right)+\gamma_{n} \phi\left(p, T_{n} x_{n}\right)+\delta_{n} \phi\left(p, S_{n} x_{n}\right) \\
\leq & \alpha_{n} \phi\left(p, x_{0}\right)+\left(1-\alpha_{n}\right) \phi\left(p, x_{n}\right) .
\end{aligned}
$$

So, $p \in C_{n}$, which implies that $F \subset C_{n}$ for all $n \geq 1$.

Since $x_{n+1}=\Pi_{C_{n}} x_{0}$ and $C_{n} \subset C_{n-1}$, then we get the following:

$$
\phi\left(x_{n}, x_{0}\right) \leq \phi\left(x_{n+1}, x_{0}\right), \quad \forall n \geq 0 .
$$


Therefore, $\left\{\phi\left(x_{n}, x_{0}\right)\right\}$ is nondecreasing. On the other hand, by Lemma 1.3, we have

$$
\phi\left(x_{n}, x_{0}\right)=\phi\left(\Pi_{C_{n-1}} x_{0}, x_{0}\right) \leq \phi\left(p, x_{0}\right)-\phi\left(p, x_{n}\right) \leq \phi\left(p, x_{0}\right)
$$

for all $p \in F(T) \subset C_{n-1}$ and for all $n \geq 1$. Therefore, $\phi\left(x_{n}, x_{0}\right)$ is also bounded. This together with (3.1) implies that the limit of $\left\{\phi\left(x_{n}, x_{0}\right)\right\}$ exists. Put the following:

$$
\lim _{n \rightarrow \infty} \phi\left(x_{n}, x_{0}\right)=d
$$

From Lemma 1.3, we have, for any positive integer $m$, that

$$
\begin{aligned}
\phi\left(x_{n+m}, x_{n+1}\right) & =\phi\left(x_{n+m}, \Pi_{C_{n}} x_{0}\right) \leq \phi\left(x_{n+m}, x_{0}\right)-\phi\left(\Pi_{C_{n}} x_{0}, x_{0}\right) \\
& =\phi\left(x_{n+m}, x_{0}\right)-\phi\left(x_{n+1}, x_{0}\right)
\end{aligned}
$$

for all $n \geq 0$. This together with (3.6) implies that

$$
\lim _{n \rightarrow \infty} \phi\left(x_{n+m}, x_{n+1}\right)=0
$$

is, uniformly for all $m$, holds. By using Lemma 1.1, we get that

$$
\lim _{n \rightarrow \infty}\left\|x_{n+m}-x_{n+1}\right\|=0
$$

is, uniformly for all $m$, holds. Then $\left\{x_{n}\right\}$ is a Cauchy sequence; therefore, there exists a point $p \in C$ such that $x_{n} \rightarrow p$.

Since $x_{n+1}=\prod_{C_{n}} x_{0} \in C_{n}$, from the definition of $C_{n}$, we have the following:

$$
\phi\left(x_{n+1}, y_{n}\right) \leq\left(1-\alpha_{n}\right) \phi\left(x_{n+1}, x_{n}\right)+\alpha_{n} \phi\left(x_{n+1}, x_{0}\right)
$$

This together with (2.10) and $\lim _{n \rightarrow \infty} \alpha_{n}=0$ implies that

$$
\lim _{n \rightarrow \infty} \phi\left(x_{n+1}, y_{n}\right)=0
$$

Therefore, by using Lemma 1.1, we obtain the following:

$$
\lim _{n \rightarrow \infty}\left\|x_{n+1}-y_{n}\right\|=0
$$

Since $J$ is uniformly norm-to-norm continuous on bounded sets, then we have the following:

$$
\lim _{n \rightarrow \infty}\left\|J x_{n+1}-J y_{n}\right\|=\lim _{n \rightarrow \infty}\left\|J x_{n+1}-J x_{n}\right\|=0 .
$$


Noticing that

$$
\begin{aligned}
\left\|J x_{n+1}-J y_{n}\right\|= & \left\|J x_{n+1}-\left(\alpha_{n} J x_{0}+\beta_{n} J x_{n}+\gamma_{n} J T_{n} x_{n}+\delta_{n} J S_{n} x_{n}\right)\right\| \\
= & \left\|\alpha_{n}\left(J x_{n+1}-J x_{0}\right)+\beta_{n}\left(J x_{n+1}-J x_{n}\right)+\gamma_{n}\left(J x_{n+1}-J T_{n} x_{n}\right)+\delta_{n}\left(J x_{n+1}-J T_{n} x_{n}\right)\right\| \\
\geq & \gamma_{n}\left\|J x_{n+1}-J T_{n} x_{n}\right\|-\delta_{n}\left\|J x_{n+1}-J S_{n} x_{n}\right\| \\
& -\alpha_{n}\left\|J x_{n+1}-J x_{0}\right\|-\beta_{n}\left\|J x_{n+1}-J x_{n}\right\|,
\end{aligned}
$$

which leads to

$$
\begin{aligned}
\gamma_{n}\left\|J x_{n+1}-J T_{n} x_{n}\right\| \leq & \left\|J x_{n+1}-J y_{n}\right\|+\alpha_{n}\left\|J x_{0}-J x_{n+1}\right\| \\
& +\beta_{n}\left\|J x_{n+1}-J x_{n}\right\|+\delta_{n}\left\|J x_{n+1}-J S_{n} x_{n}\right\| .
\end{aligned}
$$

From (2.15) and $\lim _{n \rightarrow \infty} \alpha_{n}=0, \lim _{n \rightarrow \infty} \delta_{n}=0,0<\gamma \leq \gamma_{n} \leq 1$ we obtain that

$$
\lim _{n \rightarrow \infty}\left\|J x_{n+1}-J T_{n} x_{n}\right\|=0 .
$$

Since $J^{-1}$ is also uniformly norm-to-norm continuous on bounded sets, then we obtain that

$$
\lim _{n \rightarrow \infty}\left\|x_{n+1}-T_{n} x_{n}\right\|=0
$$

This together with (2.11) implies that

$$
\lim _{n \rightarrow \infty}\left\|x_{n}-T_{n} x_{n}\right\|=0
$$

Sine $\left\{T_{n}\right\}$ and $\left\{S_{n}\right\}$ satisfy the asymptotically condition, we also have

$$
\lim _{n \rightarrow \infty}\left\|x_{n}-S_{n} x_{n}\right\|=0 .
$$

Since $x_{n} \rightarrow p$ and $\left\{T_{n}\right\}_{n=1}^{\infty},\left\{S_{n}\right\}_{n=1}^{\infty}$ are uniformly closed, we have

$$
p \in F=\left(\bigcap_{n=1}^{\infty} F\left(T_{n}\right)\right) \bigcap\left(\bigcap_{n=1}^{\infty} F\left(S_{n}\right)\right) .
$$

Finally, we prove that $p=\Pi_{F} x_{0}$, from Lemma 1.3, we have

$$
\phi\left(p, \Pi_{F} x_{0}\right)+\phi\left(\Pi_{F} x_{0}, x_{0}\right) \leq \phi\left(p, x_{0}\right)
$$

On the other hand, $x_{n+1}=\prod_{C_{n}} x_{0}$ and $F \subset C_{n}$, for all $n$. Also from Lemma 1.3, we have

$$
\phi\left(\Pi_{F} x_{0}, x_{n+1}\right)+\phi\left(x_{n+1}, x_{0}\right) \leq \phi\left(\Pi_{F} x_{0}, x_{0}\right) .
$$


By the definition of $\phi(x, y)$, we know that

$$
\lim _{n \rightarrow \infty} \phi\left(x_{n+1}, x_{0}\right)=\phi\left(p, x_{0}\right)
$$

Combining (2.24) and (2.25), we know that $\phi\left(p, x_{0}\right)=\phi\left(\Pi_{F} x_{0}, x_{0}\right)$. Therefore, it follows from the uniqueness of $\Pi_{F} x_{0}$ that $p=\Pi_{F} x_{0}$. This completes the proof.

When $\alpha_{n} \equiv 0, \delta_{n} \equiv 0$ in Theorem 2.2, we obtain the following result.

Theorem 2.3. Let $E$ be a uniformly convex and uniformly smooth Banach space, let $C$ be a nonempty closed convex subset of $E$, and let $\left\{T_{n}\right\}_{n=1}^{\infty}: C \rightarrow E$ be a uniformly closed sequence of hemi-relatively nonexpansive mappings such that $F=\bigcap_{n=1}^{\infty} F\left(T_{n}\right) \neq \emptyset$. Assume that $\left\{\alpha_{n}\right\}_{n=0}^{\infty}$ is a sequences in $[0,1]$ such that $0 \leq \alpha_{n} \leq \alpha<1$ for some constant $\alpha \in(0,1)$. Define a sequence $\left\{x_{n}\right\}$ in $C$ by the following algorithm:

$$
\begin{aligned}
x_{0} & \in C \text { arbitrarily, } \\
y_{n} & =J^{-1}\left(\alpha_{n} J x_{n}+\left(1-\alpha_{n}\right) J T_{n} x_{n}\right), \quad n \geq 1, \\
C_{n} & =\left\{z \in C_{n-1}: \phi\left(z, y_{n}\right) \leq \phi\left(z, x_{n}\right)\right\}, \quad n \geq 1, \\
C_{0} & =C, \\
x_{n+1} & =\Pi_{C_{n}} x_{0}, \quad n \geq 0 .
\end{aligned}
$$

Then $\left\{x_{n}\right\}$ converges strongly to $q=\Pi_{F} x_{0}$.

\section{Applications for Equilibrium Problem}

Let $E$ be a real Banach space, and let $E^{*}$ be the dual space of $E$. Let $C$ be a closed convex subset of $E$. Let $f$ be a bifunction from $C \times C$ to $R=(-\infty,+\infty)$. The equilibrium problem is to find $x \in C$ such that

$$
f(x, y) \geq 0, \quad \forall y \in C
$$

The set of solutions of (1.2) is denoted by $\mathrm{EP}(f)$. Given a mapping $T: C \rightarrow E^{*}$ let $f(x, y)=$ $\langle T x, y-x\rangle$ for all $x, y \in C$. Then, $p \in \operatorname{EP}(f)$ if and only if $\langle T p, y-p\rangle \geq 0$ for all $y \in C$, that is, $p$ is a solution of the variational inequality. Numerous problems in physics, optimization, and economics reduce to find a solution of (1.2). Some methods have been proposed to solve the equilibrium problem in Hilbert spaces, see, for instance, [13-15].

For solving the equilibrium problem, let us assume that a bifunction $f$ satisfies the following conditions:

(A1) $f(x, x)=0$, for all $x \in E$,

(A2) $f$ is monotone, that is, $f(x, y)+f(y, x) \leq 0$, for all $x, y \in E$,

(A3) for all $x, y, z \in E$, only $\lim \sup _{t \downarrow 0} f(t z+(1-t) x, y) \leq f(x, y)$,

(A4) for all $x \in C, f(x, \cdot)$ is convex and lower semicontinuous. 
Lemma 3.1 (Blum and Oettli [13]). Let $C$ be a closed convex subset of a smooth, strictly convex, and reflexive Banach space $E$, let $f$ be a bifunction from $C \times C$ to $R=(-\infty,+\infty)$ satisfying $(A 1)-(A 4)$, and let $r>0$ and $x \in E$. Then, there exists $z \in C$ such that

$$
f(z, y)+\frac{1}{r}\langle y-z, J z-J x\rangle \geq 0, \quad \forall y \in C
$$

Lemma 3.2 (Takahashi and Zembayashi [15]). Let $C$ be a closed convex subset of a uniformly smooth, strictly convex, and reflexive Banach space $E$, and let $f$ be a bifunction from $C \times C$ to $R=$ $(-\infty,+\infty)$ satisfying $(A 1)-(A 4)$. For $r>0$, define a mapping $T_{r}: E \rightarrow C$ as follows:

$$
T_{r}(x)=\left\{z \in C: f(z, y)+\frac{1}{r}\langle y-z, J z-J x\rangle \geq 0, \forall y \in C\right\}
$$

for all $x \in E$. Then, the following hold:

(1) $T_{r}$ is single-valued;

(2) $T_{r}$ is a firmly nonexpansive-type mapping, that is, for all $x, y \in E$,

$$
\left\langle T_{r} x-T_{r} y, J T_{r} x-J T_{r} y\right\rangle \leq\left\langle T_{r} x-T_{r} y, J x-J y\right\rangle,
$$

(3) $F\left(T_{r}\right)=\mathrm{EP}(f)$;

(4) $\mathrm{EP}(f)$ is closed and convex;

(5) $T_{r}$ is also a relatively nonexpansive mapping.

Lemma 3.3 (Takahashi and Zembayashi [15]). Let $C$ be a closed convex subset of a smooth, strictly convex, and reflexive Banach space $E$, let $f$ be a bifunction from $C \times C$ to $R=(-\infty,+\infty)$ satisfying (A1)-(A4), let $r>0$, and let $x \in E, q \in F\left(T_{r}\right)$, then the following holds:

$$
\phi\left(q, T_{r} x\right)+\phi\left(T_{r} x, x\right) \leq \phi(q, x) .
$$

Lemma 3.4. Let $E$ be a $p$-uniformly convex with $p \geq 2$ and uniformly smooth Banach space, and let $C$ be a nonempty closed convex subset of $E$. Let $f$ be a bifunction from $C \times C$ to $R=(-\infty,+\infty)$ satisfying (A1)-(A4). Let $\left\{r_{n}\right\}$ be a positive real sequence such that $\lim _{n \rightarrow \infty} r_{n}=r>0$. Then the sequence of mappings $\left\{T_{r_{n}}\right\}$ is uniformly closed.

Proof. (1) Let $\left\{x_{n}\right\}$ be a convergent sequence in $C$. Let $z_{n}=T_{r_{n}} x_{n}$ for all $n$, then

$$
\begin{gathered}
f\left(z_{n}, y\right)+\frac{1}{r_{n}}\left\langle y-z_{n}, J z_{n}-J x_{n}\right\rangle \geq 0, \quad \forall y \in C, \\
f\left(z_{n+m}, y\right)+\frac{1}{r_{n+m}}\left\langle y-z_{n+m}, J z_{n+m}-J x_{n+m}\right\rangle \geq 0, \quad \forall y \in C .
\end{gathered}
$$


Journal of Applied Mathematics

Putting $y=z_{n+m}$ in (3.6) and $y=z_{n}$ in (3.7), we have

$$
\begin{gathered}
f\left(z_{n}, z_{n+m}\right)+\frac{1}{r_{n}}\left\langle z_{n+m}-z_{n}, J z_{n}-J x_{n}\right\rangle \geq 0, \quad \forall y \in C, \\
f\left(z_{n+m}, z_{n}\right)+\frac{1}{r_{n+m}}\left\langle z_{n}-z_{n+m}, J z_{n+m}-J x_{n+m}\right\rangle \geq 0, \quad \forall y \in C .
\end{gathered}
$$

So, from (A2), we have

$$
\left\langle z_{n+m}-z_{n}, \frac{J z_{n}-J x_{n}}{r_{n}}-\frac{J z_{n+m}-J x_{n+m}}{r_{n+m}}\right\rangle \geq 0,
$$

and hence

$$
\left\langle z_{n+m}-z_{n}, J z_{n}-J x_{n}-\frac{r_{n}}{r_{n+m}}\left(J z_{n+m}-J x_{n+m}\right)\right\rangle \geq 0
$$

Thus, we have

$$
\left\langle z_{n+m}-z_{n}, J z_{n}-J z_{n+m}+J z_{n+m}-J x_{n}-\frac{r_{n}}{r_{n+m}}\left(J z_{n+m}-J x_{n+m}\right)\right\rangle \geq 0,
$$

which implies that

$$
\left\langle z_{n+m}-z_{n}, J z_{n+m}-J z_{n}\right\rangle \leq\left\langle z_{n+m}-z_{n}, J z_{n+m}-J x_{n}-\frac{r_{n}}{r_{n+m}}\left(J z_{n+m}-J x_{n+m}\right)\right\rangle \geq 0 .
$$

By using Lemma 1.6, we obtain the following:

$$
\begin{aligned}
\frac{c^{p}}{c^{p-2} p}\left\|z_{n+m}-z_{n}\right\|^{p} & \leq\left\langle z_{n+m}-z_{n}, J z_{n+m}-J x_{n}-\frac{r_{n}}{r_{n+m}}\left(J z_{n+m}-J x_{n+m}\right)\right\rangle \geq 0 \\
& =\left\langle z_{n+m}-z_{n},\left(1-\frac{r_{n}}{r_{n+m}}\right) J z_{n+m}+\frac{r_{n}}{r_{n+m}}\left(J x_{n+m}-J x_{n}\right)\right\rangle .
\end{aligned}
$$

Therefore, we get the following:

$$
\frac{c^{p}}{c^{p-2} p}\left\|z_{n+m}-z_{n}\right\|^{p-1} \leq\left|1-\frac{r_{n}}{r_{n+m}}\right|\left\|J z_{n+m}\right\|+\left\|\frac{r_{n}}{r_{n+m}} J x_{n+m}-J x_{n}\right\| .
$$

On the other hand, for any $p \in \operatorname{EP}(f)$, from $z_{n}=T_{r_{n}} x_{n}$, we have

$$
\left\|z_{n}-p\right\|=\left\|T_{r_{n}} x_{n}-p\right\| \leq\left\|x_{n}-p\right\|,
$$


so that $\left\{z_{n}\right\}$ is bounded. Since $\lim _{n \rightarrow \infty} r_{n}=r>0$, this together with (3.14) implies that $\left\{z_{n}\right\}$ is a Cauchy sequence. Hence $T_{r_{n}} x_{n}=z_{n}$ is convergent.

(2) By using Lemma 3.2, we know that

$$
\bigcap_{n=1}^{\infty} F\left(T_{r_{n}}\right)=\mathrm{EP}(f) \neq \emptyset
$$

(3) From (1) we know that, $\lim _{n \rightarrow \infty} T_{r_{n}} x$ exists for all $x \in C$. So, we can define a mapping $T$ from $C$ into itself by

$$
T x=\lim _{n \rightarrow \infty} T_{r_{n}} x, \quad \forall x \in C .
$$

It is obvious that $T$ is nonexpansive. It is easy to see that

$$
\mathrm{EP}(f)=\bigcap_{n=1}^{\infty} F\left(T_{r_{n}}\right) \subset F(T) .
$$

On the other hand, let $w \in F(T)$ and $w_{n}=T_{r_{n}} w$, we have

$$
f\left(w_{n}, y\right)+\frac{1}{r_{n}}\left\langle y-w_{n}, J w_{n}-J w\right\rangle \geq 0, \quad \forall y \in C .
$$

By (A2) we know that

$$
\frac{1}{r_{n}}\left\langle y-w_{n}, J w_{n}-J w\right\rangle \geq f\left(y, w_{n}\right), \quad \forall y \in C .
$$

Since $w_{n} \rightarrow T w=w$ and from (A4), we have $f(y, w) \leq 0$, for all $y \in C$. Then, for $t \in(0,1]$ and $y \in C$,

$$
\begin{aligned}
0 & =f(t y+(1-t) w, t y+(1-t) w) \\
& \leq t f(t y+(1-t) w, y)+(1-t) f(t y+(1-t) w, w) \\
& \leq t f(t y+(1-t) w, y) .
\end{aligned}
$$

Therefore, we have

$$
f(t y+(1-t) w, y) \geq 0
$$

Letting $t \downarrow 0$ and using (A3), we get the following:

$$
f(w, y) \geq 0, \quad \forall y \in C,
$$

and hence $w \in \operatorname{EP}(f)$. From above two respects, we know that $F(T)=\bigcap_{n=0}^{\infty} F\left(T_{r_{n}}\right)$. 
Next we show $\left\{T_{r_{n}}\right\}$ is uniformly closed. Assume $x_{n} \rightarrow x$ and $\left\|x_{n}-T_{r_{n}} x_{n}\right\| \rightarrow 0$, from above results, we know that $T x=\lim _{n \rightarrow \infty} T_{r_{n}} x$. On the other hand, from $\left\|x_{n}-T_{r_{n}} x_{n}\right\| \rightarrow 0$, we also get $\lim _{n \rightarrow \infty} T_{r_{n}} x=x$, so that $x \in F(T)=\bigcap_{n=1}^{\infty} F\left(T_{r_{n}}\right)$. That is, the sequence of mappings $\left\{T_{r_{n}}\right\}$ is uniformly closed. This completes the proof.

Theorem 3.5. Let $E$ be a $p$-uniformly convex with $p \geq 2$ and uniformly smooth Banach space, and let $C$ be a nonempty closed convex subset of $E$. Let $f$ and $g$ be two bifunctions from $C \times C$ to $R=(-\infty,+\infty)$ satisfying (A1)-(A4). Assume that $\left\{\alpha_{n}\right\}_{n=0}^{\infty},\left\{\beta_{n}\right\}_{n=0}^{\infty},\left\{\gamma_{n}\right\}_{n=0}^{\infty}$, and $\left\{\delta_{n}\right\}_{n=1}^{\infty}$ are four sequences in $[0,1]$ such that $\alpha_{n}+\beta_{n}+\gamma_{n}+\delta_{n}=1, \lim _{n \rightarrow \infty} \alpha_{n}=0, \lim _{n \rightarrow \infty} \delta_{n}=0$, and $0<\gamma \leq \gamma_{n} \leq 1$ for some constant $\gamma \in(0,1)$. Let $\left\{x_{n}\right\}$ be a sequence generated by

$$
\begin{aligned}
x_{0} & \in C \text { arbitrarily, } \\
y_{n} & =J^{-1}\left(\alpha_{n} J x_{0}+\beta_{n} J x_{n}+\gamma_{n} J T_{r_{n}} x_{n}+\delta_{n} J S_{r_{n}} x_{n}\right), \quad n \geq 1, \\
C_{n} & =\left\{z \in C_{n-1}: \phi\left(z, y_{n}\right) \leq\left(1-\alpha_{n}\right) \phi\left(z, x_{n}\right)+\alpha_{n} \phi\left(z, x_{0}\right)\right\}, \quad n \geq 1, \\
C_{0} & =C, \\
x_{n+1} & =\Pi_{C_{n}} x_{0}, \quad n \geq 0,
\end{aligned}
$$

where

$$
\begin{aligned}
& T_{r}(x)=\left\{z \in C: f(z, y)+\frac{1}{r}\langle y-z, J z-J x\rangle \geq 0, \forall y \in C\right\}, \quad \forall x \in E, \\
& S_{r}(x)=\left\{z \in C: g(z, y)+\frac{1}{r}\langle y-z, J z-J x\rangle \geq 0, \forall y \in C\right\}, \quad \forall x \in E,
\end{aligned}
$$

and $\lim _{n \rightarrow \infty} r_{n}=r>0$. Assume that the mappings $T_{n}$ and $S_{n}$ satisfy the asymptotically condition. Then $\left\{x_{n}\right\}$ converges strongly to $q=\prod_{\mathrm{EP}(f) \cap \mathrm{EP}(g)} x_{0}$.

Proof. By Lemma 3.4, $\left\{T_{r_{n}}\right\}_{n=1}^{\infty},\left\{S_{r_{n}}\right\}_{n=1}^{\infty}$ are uniformly closed; therefore, by using Theorem 2.2 and Lemma 3.2, we can obtain the conclusion of Theorem 3.5. This completes the proof.

When $\alpha_{n} \equiv 0, \delta_{n} \equiv 0$ in the Theorem 3.5, we obtain the following result.

Theorem 3.6. Let $E$ be a $p$-uniformly convex with $p \geq 2$ and uniformly smooth Banach space, and let $C$ be a nonempty closed convex subset of $E$. Let $f$ be a bifunction from $C \times C$ to $R=(-\infty,+\infty)$ satisfying (A1)-(A4). Assume that $\left\{\alpha_{n}\right\}_{n=0}^{\infty}$ is a sequences in $[0,1]$ such that $0 \leq \alpha_{n} \leq \alpha<1$ for some constant $\alpha \in(0,1)$. Define a sequence $\left\{x_{n}\right\}$ in $C$ by the following algorithm:

$$
\begin{aligned}
x_{0} & \in C \text { arbitrarily, } \\
y_{n} & =J^{-1}\left(\alpha_{n} J x_{n}+\left(1-\alpha_{n}\right) J T_{r_{n}} x_{n}\right), \quad n \geq 1, \\
C_{n} & =\left\{z \in C_{n-1}: \phi\left(z, y_{n}\right) \leq \phi\left(z, x_{n}\right)\right\}, \quad n \geq 1, \\
C_{0} & =C, \\
x_{n+1} & =\prod_{C_{n}} x_{0}, \quad n \geq 0,
\end{aligned}
$$

where $\lim _{n \rightarrow \infty} r_{n}=r>0$. Then $\left\{x_{n}\right\}$ converges strongly to $q=\Pi_{\mathrm{EP}(f)} x_{0}$. 


\section{Applications for Maximal Monotone Operators}

In this section, we apply our above results to prove some strong convergence theorem concerning maximal monotone operators in a Banach space $E$.

Let $A$ be a multivalued operator from $E$ to $E^{*}$ with domain $D(A)=\{z \in E: A z \neq \emptyset\}$ and range $R(A)=\{z \in E: z \in D(A)\}$. An operator $A$ is said to be monotone if

$$
\left\langle x_{1}-x_{2}, y_{1}-y_{2}\right\rangle \geq 0
$$

for each $x_{1}, x_{2} \in D(A)$ and $y_{1} \in A x_{1}, y_{2} \in A x_{2}$. A monotone operator $A$ is said to be maximal if it's graph $G(A)=\{(x, y): y \in A x\}$ is not properly contained in the graph of any other monotone operator. We know that if $A$ is a maximal monotone operator, then $A^{-1} 0$ is closed and convex. The following result is also wellknown.

Theorem 4.1. Let E be a reflexive, strictly convex, and smooth Banach space, and let $A$ be a monotone operator from $E$ to $E^{*}$. Then $A$ is maximal if and only if $R(J+r A)=E^{*}$. for all $r>0$.

Let $E$ be a reflexive, strictly convex, and smooth Banach space, and let $A$ be a maximal monotone operator from $E$ to $E^{*}$. Using Theorem 4.1 and strict convexity of $E$, we obtain that for every $r>0$ and $x \in E$, there exists a unique $x_{r}$ such that

$$
J x \in J x_{r}+r A x_{r} .
$$

Then we can define a single-valued mapping $J_{r}: E \rightarrow D(A)$ by $J_{r}=(J+r A)^{-1} J$ and such a $J_{r}$ is called the resolvent of $A$, we know that $A^{-1} 0=F\left(J_{r}\right)$ for all $r>0$.

Theorem 4.2. Let E be a uniformly convex and uniformly smooth Banach space, let $A$ be a maximal monotone operator from $E$ to $E^{*}$, and let $J_{r}$ be a resolvent of $A$ for $r>0$. Then for any sequence $\left\{r_{n}\right\}_{n=1}^{\infty}$ such that $\lim _{\inf _{n \rightarrow \infty}} r_{n}>0,\left\{J_{r_{n}}\right\}_{n=1}^{\infty}$ is a uniformly closed sequence of hemi-relatively nonespansive mappings.

Proof. Firstly, we show that $\left\{J_{r_{n}}\right\}_{n=1}^{\infty}$ is uniformly closed. Let $\left\{z_{n}\right\} \subset E$ be a sequence such that $z_{n} \rightarrow p$ and $\lim _{n \rightarrow \infty}\left\|z_{n}-J_{r_{n}} z_{n}\right\|=0$. Since $J$ is uniformly norm-to-norm continuous on bounded sets, we obtain that

$$
\frac{1}{r_{n}}\left(J z_{n}-J J_{r_{n}} z_{n}\right) \longrightarrow 0
$$

It follows from

$$
\frac{1}{r_{n}}\left(J z_{n}-J J_{r_{n}} z_{n}\right) \in A J_{r_{n}} z_{n}
$$

and the monotonicity of $A$ that

$$
\left\langle w-J_{r_{n}} z_{n}, w^{*}-\frac{1}{r_{n}}\left(J z_{n}-J J_{r_{n}} z_{n}\right)\right\rangle \geq 0
$$


for all $w \in D(A)$ and $w^{*} \in A w$. Letting $n \rightarrow \infty$, we have $\left\langle w-p, w^{*}\right\rangle \geq 0$ for all $w \in D(A)$ and $w^{*} \in A w$. Therefore, from the maximality of $A$, we obtain that $p \in A^{-1} 0=F\left(J_{r_{n}}\right)$ for all $n \geq 1$, that is, $p \in \bigcap_{n=1}^{\infty} F\left(J_{r_{n}}\right)$.

Next we show that $J_{r_{n}}$ is a hemi-relatively nonexpansive mapping for all $n \geq 1$. For any $w \in E$ and $p \in F\left(J_{r_{n}}\right)=A^{-1} 0$, from the monotonicity of $A$, we have

$$
\begin{aligned}
\phi\left(p, J_{r_{n}} w\right)= & \|p\|^{2}-2\left\langle p, J J_{r_{n}} w\right\rangle+\left\|J_{r_{n}} w\right\|^{2} \\
= & \|p\|^{2}+2\left\langle p, J w-J J_{r_{n}} w-J w\right\rangle+\left\|J_{r_{n}} w\right\|^{2} \\
= & \|p\|^{2}+2\left\langle p, J w-J J_{r_{n}} w\right\rangle-2\langle p, J w\rangle+\left\|J_{r_{n}} w\right\|^{2} \\
= & \|p\|^{2}-2\left\langle J_{r} w-p-J_{r_{n}} w, J w-J J_{r_{n}} w\right\rangle-2\langle p, J w\rangle+\left\|J_{r_{n}} w\right\|^{2} \\
= & \|p\|^{2}-2\left\langle J_{r_{n}} w-p, J w-J J_{r_{n}} w\right\rangle \\
& +2\left\langle J_{r_{n}} w, J w-J J_{r_{n}} w\right\rangle-2\langle p, J w\rangle+\left\|J_{r_{n}} w\right\|^{2} \\
\leq & \|p\|^{2}+2\left\langle J_{r_{n}} w, J w-J J_{r_{n}} w\right\rangle-2\langle p, J w\rangle+\left\|J_{r_{n}} w\right\|^{2} \\
= & \|p\|^{2}-2\langle p, J w\rangle+\|w\|^{2}-\left\|J_{r_{n}} w\right\|^{2}+2\left\langle J_{r_{n}} w, J w\right\rangle-\|w\|^{2} \\
= & \phi(p, w)-\phi\left(J_{r_{n}} w, w\right) \\
\leq & \phi(p, w) .
\end{aligned}
$$

This implies that $J_{r_{n}}$ is a hemi-relatively nonexpansive mapping for all $n \geq 1$. This completes the proof.

Theorem 4.3. Let $E$ be a uniformly convex and uniformly smooth Banach space, let $A$ and $B$ be two maximal monotone operators from $E$ to $E^{*}$ with nonempty common zero point set $A^{-1}(0) \cap B^{-1}(0)$, let $J_{r}^{A}$ be a resolvent of $A$ and $J_{r}^{B}$ a resolvent of $B$ for $r>0$. Assume that $\left\{\alpha_{n}\right\}_{n=0}^{\infty},\left\{\beta_{n}\right\}_{n=0}^{\infty},\left\{\gamma_{n}\right\}_{n=0}^{\infty}$, and $\left\{\delta_{n}\right\}_{n=1}^{\infty}$ are four sequences in $[0,1]$ such that $\alpha_{n}+\beta_{n}+\gamma_{n}=1, \lim _{n \rightarrow \infty} \alpha_{n}=0, \lim _{n \rightarrow \infty} \delta_{n}=0$, and $0<\gamma \leq \gamma_{n} \leq 1$ for some constant $\gamma \in(0,1)$. Let $\left\{x_{n}\right\}$ be a sequence generated by

$$
\begin{aligned}
x_{0} & \in C \text { arbitrarily, } \\
y_{n} & =J^{-1}\left(\alpha_{n} J x_{0}+\beta_{n} J x_{n}+\gamma_{n} J J_{r_{n}}^{A} x_{n}+\delta_{n} J J_{r_{n}}^{B} x_{n}\right), \quad n \geq 1, \\
C_{n} & =\left\{z \in C_{n-1}: \phi\left(z, y_{n}\right) \leq\left(1-\alpha_{n}\right) \phi\left(z, x_{n}\right)+\alpha_{n} \phi\left(z, x_{0}\right)\right\}, \quad n \geq 1, \\
C_{0} & =C, \\
x_{n+1} & =\Pi_{C_{n}} x_{0}, \quad n \geq 0,
\end{aligned}
$$

where $\liminf _{n \rightarrow \infty} r_{n}>0$. Assume that the mappings $J_{r_{n}}^{A}$ and $J_{r_{n}}^{B}$ satisfy the asymptotically condition. Then $\left\{x_{n}\right\}$ converges strongly to $q=\Pi_{A^{-1}(0) \cap B^{-1}(0)} x_{0}$. 
Proof. From Theorem 4.2, $\left\{J_{r_{n}}\right\}_{n=1}^{\infty}$ is uniformly closed countable family of hemi-relatively nonexpansive mappings, on the other hand, $A^{-1}(0)=\bigcap_{n=1}^{\infty} F\left(J_{r_{n}}\right)$, by using Theorem 2.2, we can obtain the conclusion of Theorem 4.3.

When $\alpha_{n} \equiv 0, \delta_{n} \equiv 0$ in Theorem 4.3, we obtain the following result.

Theorem 4.4. Let $E$ be a uniformly convex and uniformly smooth Banach space, let $A$ be a maximal monotone operator from $E$ to $E^{*}$ with nonempty zero point set $A^{-1}(0)$, and let $J_{r}$ be a resolvent of $A$ for $r>0$. Assume that $\left\{\alpha_{n}\right\}_{n=0}^{\infty}$ is a sequence in $[0,1]$ such that $0 \leq \alpha_{n} \leq \alpha<1$ for some constant $\alpha \in(0,1)$. Define a sequence $\left\{x_{n}\right\}$ in $C$ by the following algorithm:

$$
\begin{aligned}
x_{0} & \in C \text { arbitrarily, } \\
y_{n} & =J^{-1}\left(\alpha_{n} J x_{n}+\left(1-\alpha_{n}\right) J J_{r_{n}} x_{n}\right), \quad n \geq 1, \\
C_{n} & =\left\{z \in C_{n-1}: \phi\left(z, y_{n}\right) \leq \phi\left(z, x_{n}\right)\right\}, \quad n \geq 1, \\
C_{0} & =C, \\
x_{n+1} & =\Pi_{C_{n}} x_{0}, \quad n \geq 0,
\end{aligned}
$$

where $\liminf _{n \rightarrow \infty} r_{n}>0$. Then $\left\{x_{n}\right\}$ converges strongly to $q=\Pi_{A^{-1}(0)} x_{0}$.

\section{Examples}

Firstly, we give an example which is hemi-relatively nonexpansive mapping but not weak relatively nonexpansive mapping.

Example 5.1. Let $E=R^{n}$ and $x_{0} \neq 0$ be a any element of $E$. We define a mapping $T: E \rightarrow E$ as follows:

$$
T(x)= \begin{cases}\left(\frac{1}{2}+\frac{1}{2^{n+1}}\right) x_{0} & \text { if } x=\left(\frac{1}{2}+\frac{1}{2^{n}}\right) x_{0} \\ -x & \text { if } x \neq\left(\frac{1}{2}+\frac{1}{2^{n}}\right) x_{0}\end{cases}
$$

for $n=1,2,3, \ldots$. Next we show that $T$ is a hemi-relatively nonexpansive mapping but no weak relatively nonexpansive mapping. First, it is obvious that $F(T)=\{0\}$. In addition, it is easy to see that

$$
\|T x\| \leq\|x\|, \quad \forall x \in E .
$$


This implies that

$$
\|T x\|^{2}-\|x\|^{2} \leq 2\langle 0, J T x-J x\rangle=2\langle p, J T x-J x\rangle
$$

for all $p \in F(T)$. It follows from above inequality that

$$
\|p\|^{2}-2\langle p, J T x\rangle+\|T x\|^{2} \leq\|p\|^{2}-2\langle p, J x\rangle+\|x\|^{2},
$$

for all $p \in F(T)$ and $x \in E$. That is

$$
\phi(p, T x) \leq \phi(p, x)
$$

for all $p \in F(T)$ and $x \in E$; hence $T$ is a hemi-relatively nonexpansive mapping. Finally, we show that $T$ is not weak relatively nonexpansive mapping. In fact that, letting

$$
x_{n}=\left(\frac{1}{2}+\frac{1}{2^{n}}\right) x_{0}, \quad n=1,2,3, \ldots
$$

from the definition of $T$, we have

$$
T x_{n}=\left(\frac{1}{2}+\frac{1}{2^{n+1}}\right) x_{0}, \quad n=1,2,3, \ldots
$$

which implies that $\left\|x_{n}-T x_{n}\right\| \rightarrow 0$ and $x_{n} \rightarrow x_{0}\left(x_{n} \rightarrow x_{0}\right)$ as $n \rightarrow \infty$. That is $x_{0} \in \tilde{F}(T)$ but $x_{0} \bar{\epsilon} F(T)$.

Next, we give an example which is weak relatively nonexpansive mapping but not relatively nonexpansive mapping.

Example 5.2. Let $E=l^{2}$, where

$$
\begin{aligned}
l^{2} & =\left\{\xi=\left(\xi_{1}, \xi_{2}, \xi_{3}, \ldots, \xi_{n}, \ldots\right): \sum_{n=1}^{\infty}\left|\xi_{n}\right|^{2}<\infty\right\}, \\
\|\xi\| & =\left(\sum_{n=1}^{\infty}\left|\xi_{n}\right|^{2}\right)^{1 / 2}, \quad \forall \xi \in l^{2}, \\
\langle\xi, \eta\rangle & =\sum_{n=1}^{\infty} \xi_{n} \eta_{n}, \quad \forall \xi=\left(\xi_{1}, \xi_{2}, \xi_{3}, \ldots, \xi_{n}, \ldots\right), \eta=\left(\eta_{1}, \eta_{2}, \eta_{3}, \ldots, \eta_{n}, \ldots\right) \in l^{2} .
\end{aligned}
$$


It is well known that $l^{2}$ is a Hilbert space, so that $\left(l^{2}\right)^{*}=l^{2}$. Let $\left\{x_{n}\right\} \subset E$ be a sequence defined by

$$
\begin{aligned}
& x_{0}=(1,0,0,0, \ldots), \\
& x_{1}=(1,1,0,0, \ldots), \\
& x_{2}=(1,0,1,0,0, \ldots), \\
& x_{3}=(1,0,0,1,0,0, \ldots), \\
& \vdots \\
& x_{n}=\left(\xi_{n, 1}, \xi_{n, 2}, \xi_{n, 3}, \ldots, \xi_{n, k}, \ldots\right),
\end{aligned}
$$

where

$$
\xi_{n, k}= \begin{cases}1 & \text { if } k=1, n+1 \\ 0 & \text { if } k \neq 1, k \neq n+1\end{cases}
$$

for all $n \geq 1$. Define a mapping $T: E \rightarrow E$ as follows:

$$
T(x)= \begin{cases}\frac{n}{n+1} x_{n} & \text { if } x=x_{n}(\exists n \geq 1) \\ -x & \text { if } x \neq x_{n}(\forall n \geq 1)\end{cases}
$$

Conclusion 1. $\left\{x_{n}\right\}$ converges weakly to $x_{0}$.

Proof. For any $f=\left(\zeta_{1}, \zeta_{2}, \zeta_{3}, \ldots, \zeta_{k}, \ldots\right) \in l^{2}=\left(l^{2}\right)^{*}$, we have

$$
f\left(x_{n}-x_{0}\right)=\left\langle f, x_{n}-x_{0}\right\rangle=\sum_{k=2}^{\infty} \zeta_{k} \xi_{n, k}=\zeta_{n+1} \longrightarrow 0
$$

as $n \rightarrow \infty$. That is, $\left\{x_{n}\right\}$ converges weakly to $x_{0}$.

Conclusion 2. $\left\{x_{n}\right\}$ is not a Cauchy sequence, so that, it does not converge strongly to any element of $l^{2}$.

Proof. In fact, we have $\left\|x_{n}-x_{m}\right\|=\sqrt{2}$ for any $n \neq m$. Then $\left\{x_{n}\right\}$ is not a Cauchy sequence.

Conclusion 3. $T$ has a unique fixed point 0 , that is, $F(T)=\{0\}$.

Proof. The conclusion is obvious. 
Conclusion 4. $x_{0}$ is an asymptotic fixed point of $T$.

Proof. Since $\left\{x_{n}\right\}$ converges weakly to $x_{0}$ and

$$
\left\|T x_{n}-x_{n}\right\|=\left\|\frac{n}{n+1} x_{n}-x_{n}\right\|=\frac{1}{n+1}\left\|x_{n}\right\| \longrightarrow 0
$$

as $n \rightarrow \infty$, so that, $x_{0}$ is an asymptotic fixed point of $T$.

Conclusion 5. $T$ has a unique strong asymptotic fixed point 0 , so that $F(T)=\widetilde{F}(T)$.

Proof. In fact that, for any strong convergent sequence $\left\{z_{n}\right\} \subset E$ such that $z_{n} \rightarrow z_{0}$ and $\left\|z_{n}-T z_{n}\right\| \rightarrow 0$ as $n \rightarrow \infty$, from Conclusion 2, there exists sufficiently large nature number $N$ such that $z_{n} \neq x_{m}$, for any $n, m>N$. Then $T z_{n}=-z_{n}$ for $n>N$, and it follows from $\left\|z_{n}-T z_{n}\right\| \rightarrow 0$ that $2 z_{n} \rightarrow 0$ and hence $z_{n} \rightarrow z_{0}=0$.

Conclusion 6. $T$ is a weak relatively nonexpansive mapping.

Proof. Since $E=l^{2}$ is a Hilbert space, we have

$$
\phi(0, T x)=\|0-T x\|^{2}=\|T x\|^{2} \leq\|x\|^{2}=\|x-0\|^{2}=\phi(0, x), \quad \forall x \in E .
$$

From Conclusion 2, we have $F(T)=\widetilde{F}(T)$, then $T$ is a weak relatively nonexpansive mapping.

Conclusion 7. $T$ is not a relatively nonexpansive mapping.

Proof. From Conclusions 3 and 4 , we have $F(T) \neq \widehat{F}(T)$, so that $T$ is not a relatively nonexpansive mapping.

\section{Acknowledgment}

This project is supported by the National Natural Science Foundation of China under Grant (11071279).

\section{References}

[1] Y. I. Alber, "Metric and generalized projection operators in Banach spaces: properties and applications," in Theory and Applications of Nonlinear Operators of Accretive and Monotone Type, A. G. Kartsatos, Ed., vol. 178, pp. 15-50, Marcel Dekker, New York, NY, USA, 1996.

[2] Y. I. Alber and S. Reich, "An iterative method for solving a class of nonlinear operator equations in Banach spaces," Panamerican Mathematical Journal, vol. 4, no. 2, pp. 39-54, 1994.

[3] I. Cioranescu, Geometry of Banach Spaces, Duality Mappings and Nonlinear Problems, Kluwer Academic Publishers, Dordrecht, The Netherlands, 1990.

[4] W. Takahashi, Nonlinear Functional Analysis, Yokohama-Publishers, Yokohama, Japan, 2000.

[5] D. Butnariu, S. Reich, and A. J. Zaslavski, "Asymptotic behavior of relatively nonexpansive operators in Banach spaces," Journal of Applied Analysis, vol. 7, no. 2, pp. 151-174, 2001.

[6] Y. F. Su, J. Y. Gao, and H. Y. Zhou, "Monotone CQ algorithm of fixed points for weak relatively nonexpansive mappings and applications," Journal of Mathematical Research and Exposition, vol. 28, no. 4, pp. 957-967, 2008. 
[7] K. Nakajo and W. Takahashi, "Strong convergence theorems for nonexpansive mappings and nonexpansive semigroups," Journal of Mathematical Analysis and Applications, vol. 279, no. 2, pp. 372-379, 2003.

[8] S.. Matsushita and W. Takahashi, "A strong convergence theorem for relatively nonexpansive mappings in a Banach space," Journal of Approximation Theory, vol. 134, no. 2, pp. 257-266, 2005.

[9] S. Plubtieng and K. Ungchittrakool, "Approximation of common fixed points for a countable family of relatively nonexpansive mappings in a Banach space and applications," Nonlinear Analysis. Theory, Methods E Applications, vol. 72, no. 6, pp. 2896-2908, 2010.

[10] S. Kamimura and W. Takahashi, "Strong convergence of a proximal-type algorithm in a Banach space," SIAM Journal on Optimization, vol. 13, no. 3, pp. 938-945, 2002.

[11] C. M. Yanes and H. K. Xu, "Strong convergence of the CQ method for fixed point iteration processes," Nonlinear Analysis. Theory, Methods E Applications, vol. 64, no. 11, pp. 2400-2411, 2006.

[12] S. Matsushita and W. Takahashi, "A strong convergence theorem for relatively nonexpansive mappings in a Banach space," Journal of Approximation Theory, vol. 134, no. 2, pp. 257-266, 2005.

[13] E. Blum and W. Oettli, "From optimization and variational inequalities to equilibrium problems," The Mathematics Student, vol. 63, no. 1-4, pp. 123-145, 1994.

[14] P. L. Combettes and S. A. Hirstoaga, "Equilibrium programming in Hilbert spaces," Journal of Nonlinear and Convex Analysis, vol. 6, no. 1, pp. 117-136, 2005.

[15] W. Takahashi and K. Zembayashi, "Strong and weak convergence theorems for equilibrium problems and relatively nonexpansive mappings in Banach spaces," Nonlinear Analysis. Theory, Methods $\mathcal{E}$ Applications, vol. 70, no. 1, pp. 45-57, 2009. 


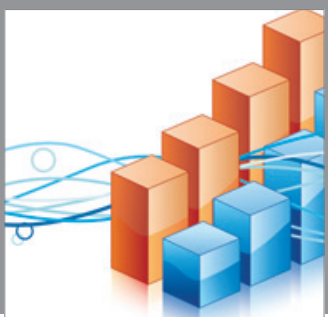

Advances in

Operations Research

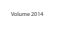

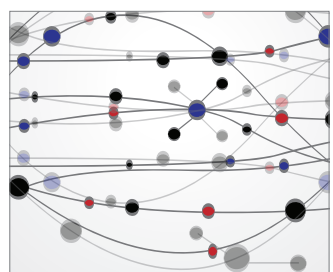

\section{The Scientific} World Journal
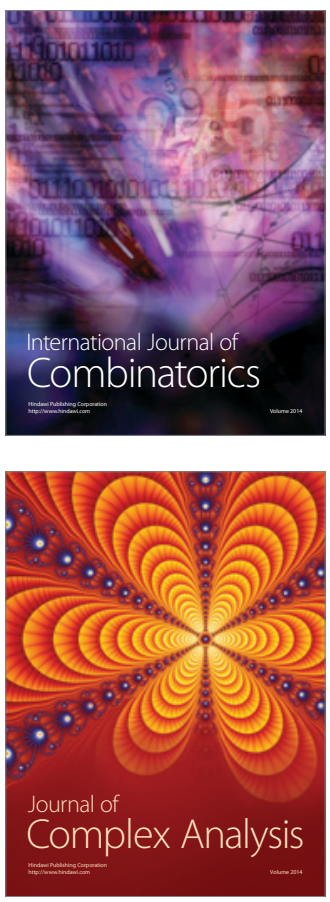

International Journal of

Mathematics and

Mathematical

Sciences
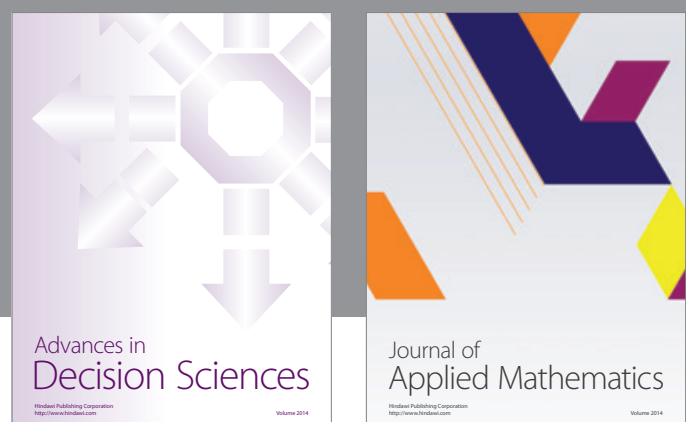

Journal of

Applied Mathematics
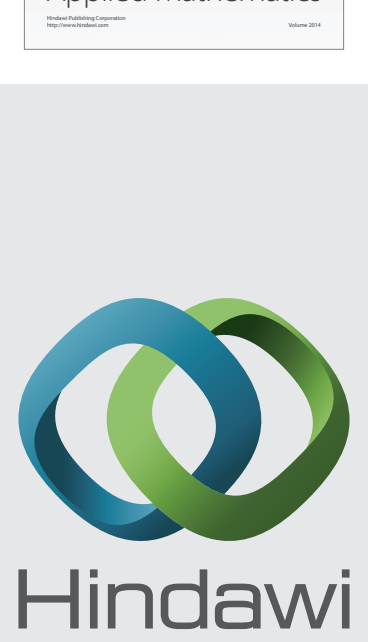

Submit your manuscripts at http://www.hindawi.com
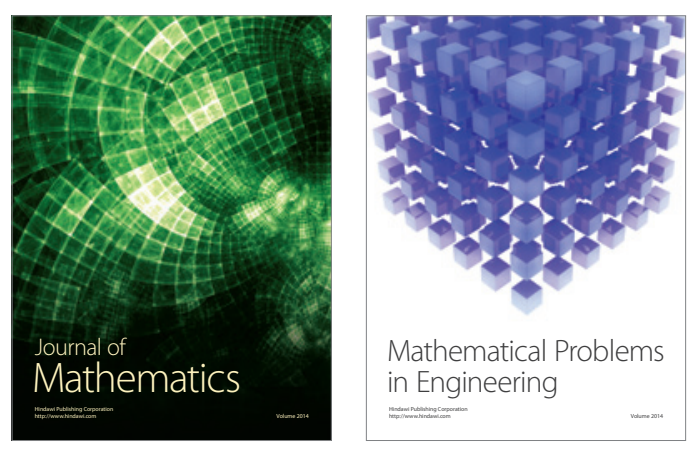

Mathematical Problems in Engineering
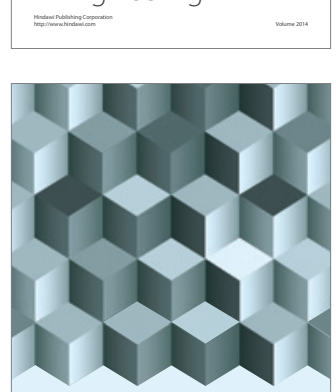

Journal of

Function Spaces
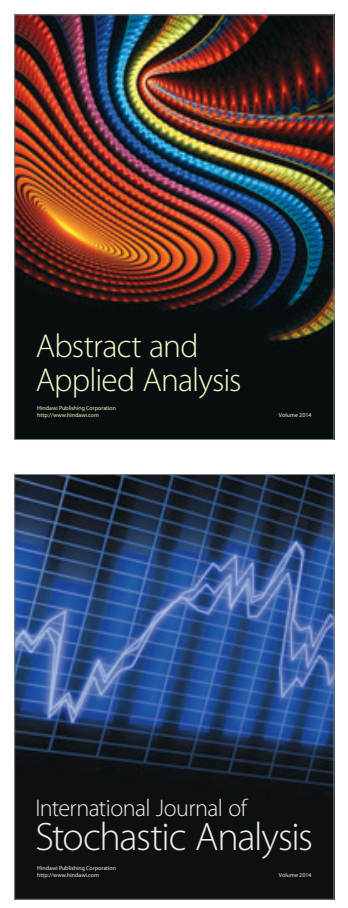

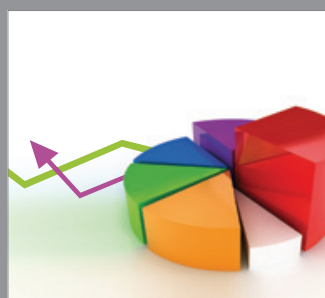

ournal of

Probability and Statistics

Promensencen
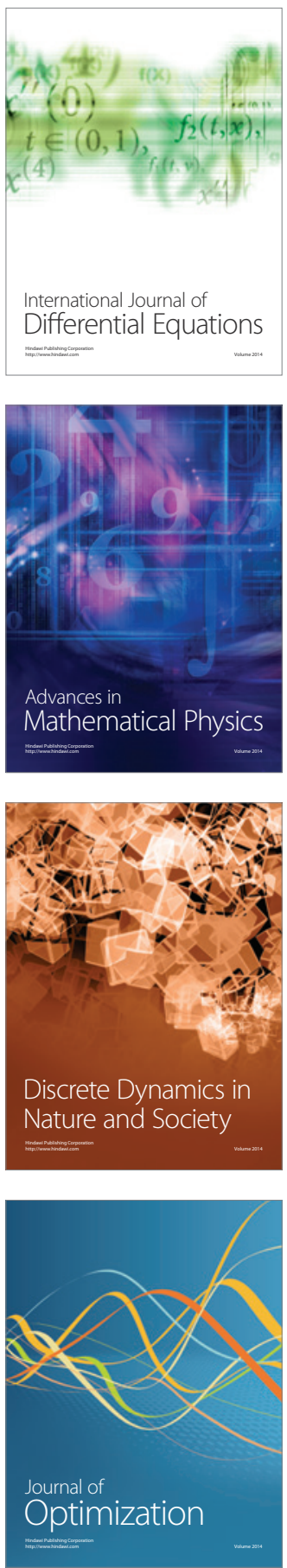